\title{
Flood Hazards and Farm Based Agricultural Production Risks Management Practices in Flood Prone Areas in Punjab, Pakistan
}

Dilshad Ahmad ( $\boldsymbol{D}$ dilshad@ciitvehari.edu.pk)

COMSATS University Islamabad, Vehari Campus Pakistan https://orcid.org/0000-0002-3991-805X Muhammad Afzal

Preston University Islamabad, Pakistan

\section{Research Article}

Keywords: Heavy rains, Floods, Risk management, Punjab, Pakistan

Posted Date: April 20th, 2021

DOI: https://doi.org/10.21203/rs.3.rs-407100/v1

License: (c) (i) This work is licensed under a Creative Commons Attribution 4.0 International License.

Read Full License 


\title{
1 Flood hazards and farm based agricultural production risks management practices in flood prone areas in Punjab, Pakistan

3

Dilshad Ahmad

Department of Management Sciences

COMSATS University Islamabad, Vehari Campus Pakistan

Corresponding author: dilshad@ ciitvehari.edu.pk https://orcid.org/0000-0002-3991-805X

11

12

13

14

15

16

17

18

19

20

21

22

23

24

25

26

27

28

29

30

31

32

33

34

35

\author{
Muhammad Afzal \\ Department of Economics \\ Preston University Islamabad, Pakistan \\ profafzal@gmail.com
}

profarza@ gmailcom 
Flood hazards and farm based agricultural production risks management practices in flood prone areas in Punjab, Pakistan

Abstract

40 Climate induced disasters more specifically the floods have caused severe damages to agriculture sector in Pakistan. These climatic risks have constrained farming community to adopt numerous risk management strategies to overcoming such risks. This research work attempted to examine the association of risk management tools with farmer's perception of risk, risk averse attitude and various socioeconomic factors. The study employed the sample data of 398 farmers from flood prone two districts of Punjab, Pakistan. To investigate the association of dependent and independent variables this study used the multivariate probit model. Results of the study illustrated as heavy rains and floods consider not significant source of risk for large farmers in the study area while for small farmer these indicated as high risks as most of small farmers were more risk averse. Estimates of multivariate probit model interpreted as age of farmer, heavy rains risk perception and landholding size were positively relationship with risk management tool of depletion of assets. Farmers education, off-farm income, age and risk averse attitude of farmer were positive whereas experience of farming were negatively linked with reduction of consumption. Furthermore, experience of farming, risk averse attitude, heavy rains and floods risk perception were positively association with diversification adoption. Flood prone farming community of the study area is more vulnerable to these climatic risks and also relying traditional strategies for risk management. There is need of some specific agriculture base measure such as crop insurance, extending formal credit and flood base measure as pre-flood warning system, flood rescue management and post flood rehabilitation to overcome these climatic risks.

Keywords: Heavy rains, Floods, Risk management, Punjab, Pakistan

\section{Introduction}

63 Floods, landslides, earthquakes, droughts and cyclones are a few major and severe natural 64 hazards the reason of higher occurrence of extreme climate change (Toe et al., 2018; Eckstein et 65 al., 2019; Ahmad et al., 2019). In present worldwide circumstances, floods are measured the 66 mainly repeated and more destructive somewhat than other hazards (Field et al., 2012; World 
67 Bank, 2013; Doocy et al., 2013 Toe et al., 2018) due to substantial association to social risk, 68 economic losses and human fatalities as mainly bared by human (Mirza, 2003; Rafique and 69 Blaschke, 2012; Ahmad and Afzal, 2021). In 2017, such type of natural disasters affected more 70 than 96 million peoples all over the world in which floods hazards affected more than $60 \%$ 71 population (World Bank, 2013; Emergency Event Database (EEDAT), 2017). In the current 72 couple of decades, increasing repetition and harshness of floods was estimated more particularly 73 in South Asian and South East Asian countries (Hirabayashi et al., 2013; Krausmann and 74 Mushtaq, 2008; Leichenko and Wescoat, 1993) where a few Asian countries India, Bangladesh, 75 China and Pakistan are highlighted as supermarkets of flood disasters (James, 2008; Ahmad et 76 al., 2019). Inadequate infrastructure, scare resources and limited flood adaptive mitigation 77 measures are significant factors of increasing flood vulnerability (Daniell et al., 2016; Abbas et 78 al., 2017) mostly for flood-prone rural community in developing countries (Zhang et al., 2011; 79 Abid et al., 2016). More particularly in developing countries, anthropogenic factors such as 80 human encroachment in rivers coupled with environmental and climatic change have played 81 major role to increasing flood hazards (Gaurav et al., 2011; Toe et al., 2018).

83 In worldwide aspect, Pakistan showed as world $5^{\text {th }}$ most natural hazards affected country 84 (Eckstein et al., 2019) owing to particularly situated in hazards prone region and facing recurrent 85 floods (Abbas et al., 2017; Ahmad and Afzal, 2021). Erratic rains, glacier melting and increasing 86 cycle of monsoon rainfalls are foremost factors related to repeated floods in interlined rivers 87 concerning upstream or downstream rivers (Teo et al., 2018; Ahmad et al., 2020). In state of 88 natural hazards as more specifically the flood hazards, Pakistan faced three worst flood disasters 89 in rapid succession in 2010, 2011 and 2014 which caused major losses of livestock, crops, 90 forestry, fishery and destructed of primary agriculture infrastructure. Flood disaster of 2010, 91 caused cumulative economic cost of 10 billion US dollars, destroy cropped area of two million 92 hectares and twenty-four million peoples were adversely affected (Rafique and Blaschke, 2012; 93 United Nations, 2011; Khan, 2011; Abid et al., 2016). Balochistan and Sindh provinces were 94 massively struck by flood hazard of 2011, which caused major destruction of crops, livestock, 95 fishery and forestry in these provinces as estimated economic loss was 3.7 billion US\$ whereas 96 the estimated cost of reconstruction and recovery as 2.7 billion US\$ (Government of Pakistan 97 (GOP), 2011; National Disaster Management Authority (NDMA), 2011). In 2014, flood caused 
98 the major losses of 367 human fatalities; damaged 1 million acre of cultivated area, for recovery

99 from flood estimated cost was 439.7 million US\$ and for resilience buildings 56.2 million US\$

100 (NDMA, 2014).

101

102 In Pakistan, agriculture is consider one of the major sector of economy due to significant 103 contribution as employing 45\% labor force of country and sharing 26\% GDP of economy 104 (Pakistan Bureau of Statistics (PBS), 2020) yet agriculture is dealing with some erratic and 105 uncertain climatic circumstances such as heavy rainfall and increasing temperature (Azam-Ali, 106 2007; Ahmad and Afzal, 2020). Agriculture in Pakistan is prominently induced by climate based 107 natural hazards drought, heavy rains, floods and other natural disasters (Khan et al., 2020; 108 Ahmad et al., 2019). In agricultural production, climate variation played severe role through 109 extreme weather scenario in Pakistan such as hailstorms, droughts, cyclones, heavy rains and 110 floods which negatively affected farm production of the country (Saqib et al., 2016; Arora, 111 2019).

113 In numerous studies, to undertake these climatic risks in agriculture farmers needs to use these 114 two informal and formal approaches these are more categorized in ex-post and ex-ante (World 115 Bank, 2013; Grubb et al., 2002). Farm level risk management ex-ante informal strategies are 116 intercropping, crop diversification, accumulated assets liquidation, income diversification, 117 adoption advance and new cropping techniques, crop sharing and informally risk pooling. Farm 118 level risk management ex-post informal strategies are assets selling, labor reallocation, mutual 119 aid and reduction of consumption. Market based formal ex-ante risk management approach 120 involves the future market contracts and insurance acquisition whereas at farm level risk 121 management market formal ex-post strategies involves with to manage risk in access of capital 122 (Ullah and Shivakoti, 2014). In these both substitute strategies risk reducing ex-ante publically 123 present extension services, infrastructure establishment (irrigation, roads, dams) and agriculture 124 system of pest management whereas public related risk management formal ex-post strategies 125 include capital transfer, formal credit access and social assistance (Saqib et al., 2016).

127 In literature, climate change and agriculture aspect significantly paying attention for the duration 128 of the couple of decades specifying the studies of climate risk assessment impacts (Schlenker and 
129 Lobell, 2010; Seo and Mendelsohn, 2008; Ali and Abdulai, 2010), studies of climate risk 130 mitigation (McCarl and Schneider, 2001; Metz et al., 2007; Bradshaw et al., 2004) and climate 131 risk adaptation studies (Abid et al., 2016; Deressa et al., 2011; Alam et al., 2019; Kato et al., 132 2011; Mugi-Ngenga et al., 2016; Bryan et al., 2013). Some studies focused the perception of 133 farmers risk and risk attitude according to various food and cash crops (Binici et al., 2003; 134 Dadzie and Acquah, 2012; Ullah et al., 2015; Sarwar and Saeed, 2013; Ali et al., 2017; Ahmad 135 and Afzal, 2020; Ahmad et al., 2019; Ahmad et al., 2020). In global scenario a number of 136 studies focused the flood hazards aspect in the scenario of farm based agricultural production 137 risks management practices in flood prone areas while this aspect more specifically in flood 138 prone areas of Punjab province of Pakistan not properly addresses according to best knowledge 139 of author. This study tried to focus this research gap more specifically in scenario of flood prone 140 areas of Punjab province Pakistan. In attendance are some considerable basis for focusing Punjab 141 province flood prone areas for this study firstly in comparing with other provinces Punjab is 142 more vulnerable of climatic risks, stress of extreme climate, floods, rising severe diseases and 143 water shortage (PDMA Punjab, 2018; PBS, 2019). Secondly, five rivers of country flow

144 throughout the fertile lands of Punjab causes major destruction of flood-prone areas agriculture 145 due to frequent erratic rains and floods (PDMA, Punjab 2018). Lastly, among all provinces 146 Punjab is major contributor agriculture production while due to these climatic risks more 147 specifically the consecutive floods from 2010 to 2014, caused significant decline in agricultural 148 production of province (BOS Punjab, 2019; PDMA Punjab, 2014). The aim of this study is to 149 examine the risk management measures association with risk perception of farmers, their attitude 150 of risk averse and various socioeconomic factors in flood prone areas of Punjab province of

151 Pakistan. This research work is classified in to four segments as introduction of the study 152 discussed in section first whereas second section illustrated the material and methods. Third 153 section of study elaborated results and discussion whereas conclusion and suggestions are 154 indicated in last section of the study.

\section{Material and methods}

$157 \quad 2.1$ Study area

158 Balochistan, Sindh, Khyber Pakhtunkhwa and Punjab are four provinces of Pakistan while 159 Punjab province was preferred for this study on the basis of few significant reasons. Firstly, this 
160 province represents $26 \%$ area of the country and the most populated as indicating $53 \%$ 161 population of the country (PBS, 2017). Secondly, this province is higher vulnerable of natural 162 hazards more particularly the floods hazards and erratic rains the reason of consecutive flowing 163 of five rivers throughout the fertile land of province (PDMA, Punjab 2017). Thirdly, southern 164 Punjab region in Punjab mainly selected for this study owing to located both sides of Pakistan's largest river Indus and repeatedly facing the flood hazards (BOS, 2017; NDMA, 2018). Fourthly, in the region of southern Punjab flood prone areas farming community of Indus River, more

167 vulnerable of flood hazards rather than other farming communities so purposely focused for this 168 study. Lastly, out of twelve higher floods risk districts of Punjab province, two higher flood 169 disasters vulnerable district Muzaffargarh and Rahim Yar Khan were (PDMA, Punjab 2014) 170 more preferably selected for the study as indicated in figure 1.

[Figure 1]

172 Muzaffargarh district consists four tehsils (sub-district in district area) Jatoi, Kot addu, 173 Muzaffargarh and Alipur, 93 union councils (Pakistan fifth administrative unit and local 174 government second tire) (GOP, 2020) with area of $8249 \mathrm{~km}^{2}$ and population of 4.32 million 175 (PBS, 2017). Muzaffargarh district consider higher vulnerable to consecutive flood disaster 176 owing to located in critical geographical scenario surrounded side by side two major rivers as 177 Indus flows western side even as Chenab flows eastern side of district (Bureau of Statistics 178 (BOS) Punjab, 2019). Hot summer and mild winter, average rainfall of $127 \mathrm{~mm}$ with lowest $1^{\circ} \mathrm{C}$ $179\left(30^{\circ} \mathrm{F}\right)$ and highest $54^{\circ} \mathrm{C}\left(129^{\circ} \mathrm{F}\right)$ temperature are some significant feathers of this area (Pakistan 180 Metrological Department (PMD), 2019). In the couple of decades, this district faced erratic 181 rainfall and frequent floods that caused foremost losses of infrastructure, crops, livestock and 182 human fatalities (PDMA Punjab, 2014) and due to lowest social progress index and cultural, 183 social and economic dimensions indicated as lower socioeconomic status district as indicated in 184 figure 2 (BOS Punjab, 2019).

186 Administratively Rahim Yar Khan district is divided in to four tehsils (sub-district in district 187 area) Khanpur, Liaqatpur, Sadiqabad and Rahim Yar Khan (GOP, 2020) by area of 11,880 km² 188 and population of 4.81million (PBS, 2017), higher vulnerable due to extreme flood disasters as 189 located on eastern bank of river Indus (PDMA Punjab, 2014). In scenario of long and extreme 190 summer Rahim Yar Khan regarded as hot region with average temperature $26.2^{\circ} \mathrm{C}$ in this area 
191 (PMD, 2019). Majority population (65\%) of district affiliated with agriculture (BOS Punjab, 192 2019) whereas during the current couple of decades because of climate change having sever 193 issues of excessive flood hazards and confronted with losses of infrastructure, livestock, crops 194 and human fatalities as indicated in figure 2 (PDMA, 2014).

2.2 Sampling technique and data collection

197 In this study multistage sampling technique was used for data collection as firstly Punjab from 198 four provinces chosen for the study area because of higher vulnerability of floods destruction 199 (PDMA, 2014). Secondly, the reason of higher flood hazards vulnerability and consecutive 200 flooding, southern Punjab region (BOS Punjab, 2019) from province specifically focused for this 201 study. Thirdly, out of twelve high risks flood hazards vulnerable two districts Rahim Yar Khan 202 and Muzaffargarh (PDMA Punjab, 2017; National Disaster Management Authority (NDMA), 203 2018) were particularly selected for the study. Fourthly, in every district two tehsils and two 204 union councils from each tehsil were purposively chosen on the basis of flood vulnerability 205 according to list provided from District Disaster Management Authority (DDMA), local land 206 record officer (patwari) and agriculture officer. Lastly, from every union council two villages 207 were selected based on higher flood destruction and vulnerability and farmer's respondents from 208 each village were randomly selected and were interviewed.

210 In procedure of data collection, households indicated the basic unit whereas the head of 211 household (female/male) consider the major respondents of this study area. In acquiring sample 212 size minimum level, this study employed the Yamane (1967) sampling method as elaborated in 213 equation 1. For this study, household heads were specifically targeted for data collection of 398 214 respondents, the population of 7\% indicated sufficient in many studies (Ullah et al., 2016; Saqib 215 et al., 2016). Sample was equally distributed in both study areas in Muzaffargarh and Rahim Yar 216 Khan. Sample size in the equation (1) indicated as n, total number of household in study area as $217 \mathrm{~N}$ whereas precision value denoted as e set as e $7 \%(0.07)$.

$$
\text { Sample Size }(n)=\frac{N}{\left(1+N e^{2}\right)}
$$

219 In the scenario of data collection, direct respondent's interaction a well developed questionnaire 220 was used and data collected from February to May 2019. In finding the adequacy and accuracy 
221 of information and avoiding ambiguity, questionnaire was used for pilot study and pre-tested 222 through 20 respondents prior to proper survey in these study areas. Five trained enumerators and 223 author himself corrected and clarified all relevant issues regarding questionnaire prior starting 224 the survey in the study area. In data collection, all respondents were clearly informed about the 225 purpose and use of data and those respondents hesitated to sharing their information was 226 replaced to others. In analyzing the collected data study households STATA and SPSS packages 227 were used. There were two sections in data analysis firstly frequency distribution and 228 percentages in descriptive statistics whereas second section illustrated the independent and 229 dependent variables association.

2.3 Study model and variables

$232 \quad$ 2.3.1 Dependent variable

233 Informal management strategies such as consumption reduction, diversification and depilation of 234 assets are dependent variables of this study. Household productive assets selling such as car, 235 motorcycle, cycle and various home appliances for managing their farming risks after floods 236 formally known as management strategy as depilation of assets as explained in equation (6) 237 denoting 1 for selling assets otherwise 0. In managing farming risks after floods households need 238 money for maintaining farming activities so they search off-farm sources of income such as 239 sending their family member abroad for remittances or working daily labor in neighboring 240 locality. In management strategy these above mentioned measures known as diversification as 241 indicated in equation (7) if adopted diversification illustrated 1 otherwise 0 . If farming 242 households reduces their non-food and food expenditures for managing farming risks known in 243 scenario of management strategy as reducing consumption if adopted indicated as 1 otherwise 0 244 as illustrated in equation (8).

$246 \quad$ 2.3.2 Independent variable

247 2.3.2.1 Risk perception

248 Risk perception as analyzing risks assessments (Wang and Roush, 2000), questions were asked 249 from the respondents for indicating the severity and incidence from risk sources and mentioning 250 the proper probability or subjective weights of Likert scale 5 points. For appropriate use of 251 respondent's response their risks were converted in low or high (Lansdowne, 1999; Cooper et al., 
252 2005) by using risk matrix approach by giving high categorization 6 to 10 whereas low level 2 to

253 5. Low risk perception indicated in unshaded area while high risk with shaded area as illustrated

254 in figure 3. In measuring the risk perception matrix approach considered more appropriate due to 255 addressing both sources of risks as severity and incidence (Ullah et al., 2015; Ahmad and Afzal, 256 2020).

[Figure 3]

$258 \quad$ 2.3.2.2 Risk attitude

259 In literature various approaches are used for estimating the farmers risk attitude whereas direct 260 and indirect two approaches are more frequently in numerous research works (Dadzie and 261 Acquah, 2012). Von Neumann and Morgenstern suggested the direct approach more properly 262 discusses the results of various levels of intolerance and tolerance for betting and so as to 263 probability concept by no mean intuitively understandable as indicated the more time consuming 264 and complicated technique (Moscardi and de Janvry, 1977).

266 In literature frequent studies (Saqib et al., 2016; Smidts, 1990; Iqbal et al., 2016; Torkamani, 267 2005; Hardaker et al., 2004; Ahmad et al., 2019; Ogurtsov et al., 2008; Ahmad and Afzal., 2020) 268 used the modified version of Equally Likely Certainty Equivalent Method (ELCEM) Neumann269 Morgenstern (N-M) model. ELCEM is recurrently applied model proxy of Elicit Utility while 270 Certainty Equivalents (CE) be stem in favor of risky outcomes chain and contest them by utility 271 values (Binici 2003). Income of household has used as utility function toward represent wealth 272 utilized in the study followed via Binici (2003). The chronological and directly share of 273 monetary and risk as measured the more monetary value and higher risk. In this scenario the 274 retorts (farmer) were inquired to indicate the value of monetary a exact outcome that causes him 275 neutral in these two risky outcomes in monetary term the PKR 280,000 like annual income 276 sample farmers as 0.5 allied probability. In the scenario of loss as 0 level of income have the 277 identical 0.5 probability farmers income is prefer in such range. In the situation of the certain 278 outcome of PKR160, 000, farmer stays indifferent. The series of outcome was indicating among 279 PKR 0 to 160,000 as farmer residue to be indifferent PKR 80,000. In more procedure farmer 280 through selecting range in PKR 80,000 say as the equal promises with the PKR 0 and illustrated 281 unconcerned in PKR 40,000. In the other amount of PKR 30,000 with the unresponsive standing 282 of farmer, experimentation was repeated. In higher series of PKR 160,000 to 280,000, farmers 
283 involve has come to a decision and keep on indifferent in PKR 180,000. In a more sequence of 284 PKR 180,000 to 280,000, farmers stay neutral in PKR 210,000. The recurrence of 285 experimentation linked of probabilities numerous CE points be resultant.

286 In favor of instance, the value of utility for example PKR 40,000 measured as

$$
U(40,000)=0.5 u(0)+0.5 u(80,000)=0.5(0)+0.5(1)=0.5
$$

288 Consequently to find different CE and identical them with values of utility, function of cubic 289 utility was applied for measuring utility of each individual respondent. The given equation 290 illustrated the cubic utility function

$$
U(w)=\mathrm{a}_{1}+\mathrm{a}_{2} w+\mathrm{a}_{3} w^{2}+\mathrm{a}_{4} w^{3}
$$

Risk indifferent, risk preferring and risk aversion attitude all of such are consistent with cubic utility function (Binic et al., 2003). In general utility procedure accessed through ordinary scale, utility function form on an ordinary scale be able to distorted in risk aversion quantitative degree know as absolute risk aversion (Arrow, 1964; Raskin, 1986; Pratt, 1964). Absolute risk aversion in arithmetically form can be written such as

$$
r_{\alpha}(W)=-\frac{U^{\prime}(W)}{U^{\prime}(W)}
$$

Absolute risk aversion coefficients are indicated in above equation such as $\mathrm{ra}(\mathrm{W})$ while the wealth (W) second order and first order derivatives indicated as U' and U'. Olarinde, (2007) indicated as for wealth the income is supernumerary. Respondents risk behavior justify through coefficients value sign, respondent is risk-averse if absolute risk aversion coefficient values as positive sign, respondents as risk taker illustrated through coefficient absolute risk aversion 305 negative sign while zero coefficient sign as unresponsive to risk. This empirical analysis includes 306 risk attitude of respondent as risk aversion behavior if yes as 1 otherwise 0 .

$$
\begin{array}{ll}
\text { Risk aversion } & =r_{a}(w)<0 \\
\text { Risk neutral } & =r_{a}(w)=0 \\
\text { Risk preference } & =r_{a}(w)>0
\end{array}
$$

\subsubsection{Socioeconomic characteristics of farm households}


312 Risk management decision of farmers are significantly influenced by farmers characteristics of

313 socioeconomics such as farmers off-farm income, education and age (Sherrick et al., 2004).

314 Owned land share in cultivation, off-farm monthly income, size of farm, farmer's education,

315 farming experience and farmers age were some significant demographic and socioeconomic

316 factors used in this study. Measurement units of these factors were as monetary unit as PKR for

317 annual off-farm income, schooling years for education, cultivated land in acres for farm size,

318 experience and age in years.

\subsection{Empirical model}

321 In estimating the influence of simultaneous independent variables over strategies of risk 322 management this study applied the multivariate probit model as indicated in equation (5).

323 Multivariate probit model be connected the form of model of binary regression which 324 simultaneously estimates the impact of explanatory variables on more than one dependent 325 variable. In this model it is allowed the error term is freely linked. In this research work for 326 managing farming risks, farmers have employed informal three tools of risk management as 327 study focused to adoption these tools simultaneously. In simultaneously adoption decision of 328 farmer's tools of risk management, multivariate model is more feasible and adopted for empirical 329 estimation in this study as indicated below in equation (5)

$$
Y_{i j}=X_{i j} \beta_{i}+\varepsilon_{i j}
$$

331 Dependent variable denoted as Yij, alternative utilized risk management as $\mathrm{j}=1 . .3$ whereas ith 332 farmers indicated as $\mathrm{i}=1 \ldots . . . \mathrm{n}$, Independent variables vectors $\mathrm{Xij}$ which causes to affect adoption 333 decision risk management, estimated parameters coefficient illustrated as $\beta \mathrm{i}$, the error term 334 unobserved that distributed normally with constant variance and zero mean explained as ci. In 335 such scenario each binary variable Yij such above equation indicated as system of equations as 336 used for empirical estimation.

In the above mentioned various three equations each equation has different dependent variable

$341 \mathrm{Y} 1, \mathrm{Y} 2$ and $\mathrm{Y} 3$ indicating the different risk management strategy as illustrating 1 in $\mathrm{Yj}$ and 342 otherwise 0. 


\section{Results and discussion}

344 In the scenario of landholding size, study area farmers were categorized in to three groups 345 according to land holding size as above five hectares denoted large farmers, holding land above 346 two to five hectares illustrated medium farmers and up to two hectares highlighted small farmers 347 (Saqib et al., 2016; Ullah et al., 2015). The different variables of categorized farmers groups and 348 number of farmers in various groups as large farmers (64), medium farmers (108) and small 349 farmers (226) as indicated in table 1. In the education status, majority of $64.57 \%$ farmers groups 350 is literate whereas the higher literacy rate indicated in large farmers rather than medium and 351 small farmers. Majority of farmers $54.77 \%$ are young owing to age group up to 40 years as 352 compared to other age groups in all categorized farmers as highlighted in table 1. In farming 353 experience, majority of farmers $46.98 \%$ in all categorized farmer groups having the experience 354 up to 20 years whereas limited farmers $20.85 \%$ have farming experience above 30 years. In off355 farm income scenario majority of farmers have off-farm income up to PKR200, 000 while 356 limited farmer $28.39 \%$ have off-farm income more than PKR 400,000.

$358 \quad 3.1$ Farmer's perception of risk

359 3.1.1 Heavy rains and floods risk perception

360 Farmer's heavy rains risk perceptions have illustrated in two scenarios low risk perception of 361 heavy rains and high risk perceptions of heavy rains. In total sample size majority of farmers $36281.12 \%$ have heavy rains high risk perception whereas the limited number of farmers $18.88 \%$ has 363 low heavy rains risks in the study area. In categorized groups of farmers, small and medium 364 farmers group were more vulnerable to heavy rains so majority small $82.74 \%$ and medium $36580.56 \%$ farmers indicated the higher risk perception of heavy rains rather than large farmers 366 group. Such scenario was empirically proved as heavy rains caused destruction of their crops and 367 other resources in 2010 and onward. In large farmers group almost 23.44\% farmers consider 368 heavy rains as low risk for their crops and other resources. The value of Chi-square 1percent 369 confidence level highlights heavy rain risk perception of various farmers not alike.

[Table 2]

371 Farmers agricultural risk management decisions are significantly influenced by farmers risk 372 perception of climate hazards. Large, medium and small are three groups in which farmers to be 373 categorized. In the scenario of farmers total sample size majority of farmer $74.37 \%$ have high 
374 risk perception of flood disasters whereas almost $1 / 4$ of farmers $25.63 \%$ do not consider the flood 375 as major risk to their crops and fields (Khan et al., 2020). Majority in all categorized farmers groups small (73.89\%), medium (76.85\%) and large farmer (71.87\%) have higher risk perception

377 of flood whereas the limited small (26.11\%) medium $(23.15 \%)$ and large (28.13\%) group farmer

378 have lower risk perception of flood hazards in this study area. These results are alike by way of 379 the studies of Rana and Routray (2016) and Rizwan et al., (2020) as indicated due poor 380 infrastructure, limited resources and inadequate adaption measures flood prone areas of Punjab 381 province are higher vulnerable to flood disasters. The value of Chi-square less than1percent 382 confidence level highlights differences in risk perception of farmers of flood as an exogenous 383 factor. Majority of farmers perceived higher perception risk about flood whereas somewhat 384 dissimilar.

385 Floods are considered most destructive natural hazards in the scenario of economic losses and 386 human fatalities (Ali, 2007) rather than other natural hazards that is why farmers highlighted 387 perception of high risk about heavy rains and floods (Qasim et al., 2015; Khan et al., 2010; Deen, 388 2015). Massive destruction and heavy losses of agriculture more specifically in flood prone areas 389 in floods of 2010, 2011 and 2014 generated higher perception of heavy rains and flood risks 390 (Ahmad et al., 2019; Saqib et al., 2016).

3923.2 Risk attitude

393 In obtaining the first and second derivative the value of coefficient aversion was calculated. 394 Farmer in the study area were categorized in three groups large, medium and small according to 395 their land holding size and their risk attitude are compared in categorized groups as indicated in 396 table 3. In large farmers group almost 2/3 farmers $67.19 \%$ are risk averse whereas $1 / 3$ farmers $39732.81 \%$ are risk lover. Limited numbers $14.8 \%$ of farmers in medium farmers group are risk 398 lover while majority $85.2 \%$ is risk averse. In small farmers group majority farmers $71.68 \%$ are 399 risk averse and small numbers $28.32 \%$ are risk lover. In overall scenario majority of farmers in 400 all groups are risk averse $74.62 \%$ as compared to risk lovers $25.38 \%$ whereas medium farmers 401 group among all groups higher risk averse relatively to small and large farmers. Farmer's group 402 differences were at 1 percent level of significance. These findings of risk attitude regarding risk 403 averse are consistent to research work of Ullah et al., (2015), Kitonyoh, (2015), Ahmad et al., 404 (2019) and Iqbal et al., (2016). 
$406 \quad 3.3$ Tools of risk management

407 Diversification, reduction of consumption and depletion of assets are some management 408 decisions and three commonly and significantly tools used for risk management strategies also 409 employed in this study. In district scenario, 65\% farmers in Rahim Yar Khan and 53\% in 410 Muzaffargarh district are using the practices of diversification as indicated in figure 4. In 411 Muzaffargarh 74\% and 69\% in Rahim Yar Khan farmers are engaged with practices about 412 reduction of consumption strategies. Regarding the depletion of assets $68 \%$ farmers in 413 Muzaffargarh and $61 \%$ in Rahim Yar Khan are using this practice for risk management. In 414 overall scenario regarding risk management tools adoption decisions in both districts, reduction 415 of consumption $71.5 \%$ indicated the more practised tool in districts rather than diversification $41659 \%$ and depletion of assets $64.5 \%$ as indicated in figure 4.

[Figure 4]

418 Risk management strategies adopted among categorized large, medium and small farming groups 419 illustrated in figure 5. Majority of small farmers more preferably engaged with practices the 420 reduction of consumption $54.29 \%$ and depletion of assets $47.56 \%$ rather than large $(21.85 \%$, $42123.86 \%)$ and medium farmers $(20.46 \%, 31.98 \%)$. Large farmers group more preferably engaged 422 with diversification tools (43.76\%) rather than medium (29.49\%) and small (26.75) farmers. All 423 categorized farmers groups are more or less engaged in all risk management practices as 424 illustrated in figure 5.

[Figure 5]

426 3.3.1 Risk management decision correlation

427 Farmers risk management tools application decisions correlation illustrated in the table 4. In 428 multivariate models equations coefficient correlation is pair wise correlation in error terms. This 429 coefficient correlation is at 99 percent level of significance. These estimates illustrated as 430 correlation in equations and fitness of simultaneous adoption models. This study employed the 431 multivariate probit model and estimated positive sign of model highlights as on the similar 432 instance farmers go away for further management practices. 
437 Multivariate models are used for estimating the adoption and management tools are significantly

438 correlated with each others as illustrated in correlation table 4. Multivariate probit model 439 parameters outcomes indicated the decisions of concurrent adoption risk management as 440 highlighted in table 5.

$442 \quad 3.4 .1$ Factors determine depletion of assets

443 Farmers in the study area indicated the depletion of assets as one of the significant tool of 444 standard risk management. Estimates of the model indicated as age positively (0.036) and 445 significantly $(\mathrm{p}<0.02)$ associated with depletion of assets as aged farmers highly deplete their 446 assets rather than young farmers as indicated in table 5. The reason is that young farmers manage 447 their farming risks through working as labor in markets whereas aged farmers cannot participate 448 in such working practices so deplete their assets for managing farming activates. These 449 conclusions are alike the research works of Baas et al., (2008), Yassin, (2011) and Saqib et al., 450 (2021). Results illustrated the negative association in farming experience and depletion of assets 451 showing as experienced farmers rather than depleting assets more prefer to adopt other strategies 452 for managing farming activities as compared to inexperience farmers. These results are alike 453 with the studies of Saqib et al., (2016) and Ullah and Shivakoti, (2014). Estimates of study 454 illustrated the negative link in off-farm income and depletion of assets as highlighting that those 455 farmers having adequate off-farm income do not deplete their assets and manage farming 456 activates through off-farm income. Farmers having limited of no off-farm income deplete their 457 assets for managing farming risks and activities. These results are alike with the study of Dixon 458 et al., (2001) and Saqib et al., (2021). The estimates of model showed positive relationship in 459 depletion of assets and size of landholding as indicating as land size increasing farmers more 460 willing to deplete assets for managing farming activities. The reason is that farmers with 461 increasing land size have to purchase machinery and other inputs to managing additional land 462 farming activates or floods so sell their more liquid assets as home appliances whereas the 463 farmers with small farm size relatively less need of resource so randomly need for resources 464 depletion as compared to large farm size farmers. These finding are contradictory with the 465 studies of Kahan, (2008) and Saqib et al., (2021). In estimates of the study, heavy rains risk 466 perception positive related with depletion of assets indicating as heavy rains causes major losses 
467 of crops and structure of farm so for managing these farming activities farmers deplete their 468 assets. These conclusions are alike by the studies of Ullah and Shivakoti, (2014) and Saqib et al., 469 (2021).

$471 \quad 3.4 .2$ Factors determine reduction of consumption

472 Reduction of consumption is another risk management strategy as majorly experienced in small

473 farmers also closely linked with farmer's socioeconomic factors as indicated in table 5. Estimates

474 of the model illustrated as positive association in education of farmer and reduction of 475 consumption indicating as increase in farmers education increases reduction in farmer's 476 consumption as due to higher schooling farmers more focus to allocate more resources to risk 477 adaptation measures of farming through reducing the consumption. These conclusions are 478 consistent with the study of Saqib et al., (2021). Results of the study illustrated the positive 479 relationship in off-farm income and reduction in consumption as highlighting the off-farm 480 income increases farmer reduction in consumption increases. The reason is that as farmers off481 farm income increase it reduces its consumption and allocates more resources off-farm and in 482 farm practices. These results are alike with the studies of Ullah, (2014) and Saqib et al., (2021) 483 while in dissimilar with the study of Velandia et al., (2009). Results of the study indicated the 484 negative relationship in experience of farming and reduction of consumption for risk 485 management practice, illustrating as experienced farmers more prefer to manage farming risk 486 and activates through adopting other risk management sources rather than reduction in 487 consumption. In other scenario, inexperienced farmers prefer to reduction in consumption for 488 managing farming activates and risks. These conclusions are alike with the research of Adnan et 489 al., (2020) and Saqib et al., (2021). Estimates indicated the positive relationship in farmers risk 490 attitude and reduction in consumption highlighting as farmers becomes more risk averse they 491 prefer to sure more risk management practices for managing farming activites and risk through 492 adopting reduction in consumption. Farmer having risk lover attitude do not prefer to reduction 493 of consumption. These results are similar with research of Saqib et al., (2016) and Ullah et al., 494 (2015).

495

496 3.4.3 Factors determining the strategy of diversification 
497 In all categorized farmers group's uncertainty and risk prevails as showed in the empirical 498 estimates significant finding of the study. Estimates of diversification illustrated as farmer's 499 education, age, off-farm income, risk attitude of farmers, heavy rains and flood perception were

500 significantly relationship with diversification as indicated in table 5. Results indicated as 501 negative link of farmer's age and diversification indicating as age increase farmers become less 502 prefer to adoption of diversification. These estimates indicated as aged farmers less prefer to 503 adoption of risks management farming rather than young farmers as such conclusions are alike 504 with the research of Deressa et al., (2010), Ashfaq et al., (2008), Dadzie and Acquah et al., 505 (2012), Mesfin et al., (2011), Rehima et al., (2013), Jensen and Pope, (2014) and Mashi et al., 506 (2020). Estimates indicated as among categorized farmers groups large farmer are higher 507 adopting the diversifications because they are higher risk averse rather than small and medium 508 farmers as finding consistent with the study of Saqib et al., (2021). Results indicated as positive 509 and significant relationship in diversification and heavy rains risk perception and floods. 510 Majority of farmers have more heavy rains risk perception and flood highlighting farmers more 511 adopting diversification more risk averse and more prefer risk management measures. These 512 findings are alike with the studies of Van Winsen, (2014), Zulfiqar et al., (2016) and Mashi et al., 513 (2020).

\section{4. Conclusion and suggestions}

516 Farmers risk perception play significant role in farming decisions in application of risk 517 management strategies. In categorized farmers groups, majority of small farmers believe heavy 518 rains and floods foremost risk to their farming. Risk attitude of farmer estimated in the study 519 illustrated as majority of farmers are risk averse in all categorized groups. Large farmers mostly 520 engaged in adopting diversification tool for risk management whereas small farmer mostly 521 focused to adopting reduction of consumption and depleting assets for risk management. 522 Findings of the study indicated the close relationship in socioeconomic factors and risk 523 management tools depleting assets, reduction of consumption and diversification. All categorized 524 groups of farmers were more exposed to heavy rains and floods while small group farmers were 525 highly exposed due to limited land holding size and more risk averse about these risks. 526 Mainstream study area farmers are higher vulnerable due to heavy rains and floods because of 527 practicing the traditional tools for adaptation to climatic disasters. Flood prone farmers more 
528 specifically need to provide crop insurance and low interest formal loans as they can use advance 529 tools to manage these climatic risks. In disaster scenario disaster management authorities need to

530 help these flood prone farmers through early warning information, escape from disaster and 531 rehabilitation after disaster.

\section{Declarations}

534 Ethical Approval

535 Ethical approval taken from the COMSATS University Vehari campus, ethical approval

536 committee

537 Consent to Participate

538 Not applicable

539 Consent to Publish

540 Not applicable

541 Authors Contributions

542 DA analyzed data, methodology, results and discussion, conclusion and suggestions and 543 manuscript write up whereas both DA and MA finalized and proof read the manuscript and both

544 authors read and approved the final manuscript.

$545 \quad$ Funding

546 This study has no funding from any institution or any donor agency.

547 Competing Interests

548 The authors declare that they have no competing interest.

550 Availability of data and materials

551 The datasets used and/or analyzed during the current study are available from the corresponding 552 author on reasonable request.

\section{References}

555 Abbas, G., Ahmad, S., Ahmad, A., Nasim, W., Fatima, Z., Hussain, S., ... \& Hoogenboom, G. 556 (2017). Quantification the impacts of climate change and crop management on phenology of maize-based cropping system in Punjab, Pakistan. Agricultural and Forest Meteorology, 247, 42-55.

Adnan, K. M., Ying, L., Ayoub, Z., Sarker, S. A., Menhas, R., Chen, F., \& Yu, M. M. (2020). Contract Farming, Diversification and Precautionary Savings. Agriculture, 10(8), 351. 
Ahmad, D., \& Afzal, M. (2020). Flood hazards and factors influencing household flood perception and mitigation strategies in Pakistan. Environmental Science and Pollution Research, 1-13.

Ahmad, D., \& Afzal, M. (2020). Flood hazards, human displacement and food insecurity in rural riverine areas of Punjab, Pakistan: policy implications. Environmental Science and Pollution Research, 1-15.

Ahmad, D., \& Afzal, M. (2021). Impact of climate change on pastoralists' resilience and sustainable mitigation in Punjab, Pakistan. Environment, Development and Sustainability, $1-21$.

Ahmad, D., Afzal, M., \& Rauf, A. (2019). Analysis of wheat farmers' risk perceptions and attitudes: evidence from Punjab, Pakistan. Natural Hazards, 95(3), 845-861.

Alam, M. M., Siwar, C., bin Toriman, M. E., Molla, R. I., \& Talib, B. (2019). Climate Change Induced Adaptation by Paddy Farmers in Malaysia.

Ali, A. M. S. (2007). September 2004 flood event in southwestern Bangladesh: a study of its nature, causes, and human perception and adjustments to a new hazard. Natural Hazards, 40(1), 89-111.

Ali, A., \& Abdulai, A. (2010). The adoption of genetically modified cotton and poverty reduction in Pakistan. Journal of Agricultural Economics, 61(1), 175-192.

Ali, S., Liu, Y., Ishaq, M., Shah, T., Ilyas, A., \& Din, I. U. (2017). Climate change and its impact on the yield of major food crops: Evidence from Pakistan. Foods, 6(6), 39.

Arora, N. K. (2019). Impact of climate change on agriculture production and its sustainable solutions.

Arrow K.J. (1964): The role of securities in the optimal allocation of risk bearing. Rev. Econ. Std. 31: 91-96.

Ashfaq, M., Hassan, S., Naseer, M. Z., Baig, I. A., \& Asma, J. (2008). Factors affecting farm diversification in rice-wheat. Pakistan Journal of Agricultural Sciences, 45(3), 91-94.

Azam-Ali, S. (2007). Agricultural diversification: The potential for underutilised. In Rivista di Biologia/Biology Forum (Vol. 1, No. 1, pp. 27-28).

Baas, S., Ramamasy, S., Dey de Pryck, J., \& Battista, F. (2008). Disaster risk management systems analysis: A guide book. 
Binici, T., Koc, A. A., Zulauf, C. R., \& Bayaner, A. (2003). Risk attitudes of farmers in terms of risk aversion: A case study of lower Seyhan plain farmers in Adana province, Turkey. Turkish Journal of Agriculture and Forestry, 27(5), 305-312.

Board of Statistics (BOS) Punjab (2017). Punjab statistics 2017, Statistical Division Punjab Government of Punjab, Lahore, Punjab, Pakistan

Board of Statistics (BOS) Punjab (2019). Punjab statistics 2019, Statistical Division Punjab Government of Punjab, Lahore, Punjab, Pakistan

Bradshaw, B., Dolan, H., \& Smit, B. (2004). Farm-level adaptation to climatic variability and change: crop diversification in the Canadian prairies. Climatic change, 67(1), 119-141.

Bryan, E., Ringler, C., Okoba, B., Roncoli, C., Silvestri, S., \& Herrero, M. (2013). Adapting agriculture to climate change in Kenya: Household strategies and determinants. Journal of environmental management, 114, 26-35.

Cooper, D. F., Grey, S., Raymond, G., \& Walker, P. (2005). Project risk management guidelines: Managing risk in large projects and complex procurements. John wiley \& sons, Inc..

Dadzie, S. K. N., \& Acquah, H. D. G. (2012). Attitudes toward risk and coping responses: The case of food crop farmers at Agona Duakwa in Agona East District of Ghana.

Daniell, H., Lin, C. S., Yu, M., \& Chang, W. J. (2016). Chloroplast genomes: diversity, evolution, and applications in genetic engineering. Genome biology, 17(1), 1-29.

Deen, S. (2015). Pakistan 2010 floods. Policy gaps in disaster preparedness and response. International journal of disaster risk reduction, 12, 341-349.

Deressa, T. T., Hassan, R. M., \& Ringler, C. (2011). Perception of and adaptation to climate change by farmers in the Nile basin of Ethiopia. The Journal of Agricultural Science, 149(1), 23-31.

Deressa, T. T., Ringler, C., \& Hassan, R. M. (2010). Factors affecting the choices of coping strategies for climate extremes. The case of farmers in the Nile Basin of Ethiopia IFPRI Discussion Paper, 1032.

Dixon, J., Gulliver, A., Gibbon, D., \& Hall, M. (2001). Farming systems and poverty: improving farmers' livelihoods in a changing world. Summary. 
621 Doocy, S., Daniels, A., Packer, C., Dick, A., \& Kirsch, T. D. (2013). The human impact of earthquakes: a historical review of events 1980-2009 and systematic literature review. PLoS currents, 5.

624 Eckstein, D., Künzel, V., Schäfer, L., \& Winges, M. (2019). Global climate risk index 2020. Bonn: Germanwatch.

Emergency Event Database (2017) The International Disaster Database, Emergency Event Database (EE-DAT), 2017

Field, C. B., Barros, V., Stocker, T. F., \& Dahe, Q. (Eds.). (2012). Managing the risks of extreme events and disasters to advance climate change adaptation: special report of the intergovernmental panel on climate change. Cambridge University Press. Finance Statistical Division, Government of Pakistan

Gaurav, K., Sinha, R., \& Panda, P. K. (2011). The Indus flood of 2010 in Pakistan: a perspective analysis using remote sensing data. Natural hazards, 59(3), 1815-1826.

GOP (2011) Economic Survey of Pakistan 2010-11, Pakistan Bureau of Statistics, Ministry of Finance Government of Pakistan. http://www.finance.gov.pk/survey_1011.html

GOP (2020) Economic Survey of Pakistan 2019-20, Pakistan Bureau of Statistics, Ministry of Finance Government of Pakistan. http://www.finance.gov.pk/survey_1920.html

Hardaker, J. B. (Ed.). (2004). Coping with risk in agriculture. Cabi.

Hirabayashi, Y., Mahendran, R., Koirala, S., Konoshima, L., Yamazaki, D., Watanabe, S., ... \& Kanae, S. (2013). Global flood risk under climate change. Nature Climate Change, 3(9),

Iqbal, M. A., Ping, Q., Abid, M., Kazmi, S. M. M., \& Rizwan, M. (2016). Assessing risk

James, E. (2008). Getting ahead of the next disaster: recent preparedness efforts in Indonesia. Development in Practice, 18(3), 424-429.

650 Jensen, F. E., \& Pope, R. D. (2004). Agricultural precautionary wealth. Journal of Agricultural 651 and Resource Economics, 17-30. 
KAHAN, D. (2008). Farm management extension guide-Managing risk in farming.[Online]. FAO Rome.

654 Kato, E., Ringler, C., Yesuf, M., \& Bryan, E. (2011). Soil and water conservation technologies: a buffer against production risk in the face of climate change? Insights from the Nile basin in Ethiopia. Agricultural Economics, 42(5), 593-604.

Khan, A. N. (2011). Analysis of flood causes and associated socio-economic damages in the Hindukush region. Natural hazards, 59(3), 1239.

Khan, A. N., Khan, S. N., \& Ali, A. M. J. A. D. (2010). Analysis of damages caused by flood2010 in district Peshawar. J. Sc. Tech. Univ. Peshawar, 36, 11-16.

Khan, I., Lei, H., Shah, I. A., Ali, I., Khan, I., Muhammad, I., ... \& Javed, T. (2020). Farm households' risk perception, attitude and adaptation strategies in dealing with climate change: Promise and perils from rural Pakistan. Land use policy, 91, 104395.

Kitonyo, C. K. (2015). A Farm Level Analysis of Risk Attitude, sources and risk measurement strategies among Farmers in Trans Nzoia County, Kenya (Doctoral dissertation, Moi University).

Krausmann, E., \& Mushtaq, F. (2008). A qualitative Natech damage scale for the impact of floods on selected industrial facilities. Natural Hazards, 46(2), 179-197.

Lansdowne, Z. F. (1999). Risk matrix: an approach for prioritizing risks and tracking risk mitigation progress. Proceedings of the 30th Annual Project Management Institute, Philadelphia, PA, October, 10-16.

Leichenko, R. M., \& Wescoat Jr, J. L. (1993). Environmental impacts of climate change and water development in the Indus delta region. International Journal of Water Resources Development, 9(3), 247-261.

Mashi, S. A., Inkani, A. I., Obaro, O., \& Asanarimam, A. S. (2020). Community perception, response and adaptation strategies towards flood risk in a traditional African city. Natural Hazards, 103, 1727-1759.

McCarl, B. A., \& Schneider, U. A. (2001). Greenhouse gas mitigation in US agriculture and forestry.

Mesfin, W., Fufa, B., \& Haji, J. (2011). Pattern, trend and determinants of crop diversification: empirical evidence from smallholders in eastern Ethiopia. Journal of Economics and Sustainable Development, 2(8), 78-89. 
Metz, B., Davidson, O. R., Bosch, P. R., Dave, R., \& Meyer, L. A. (2007). Contribution of working group III to the fourth assessment report of the intergovernmental panel on climate change, 2007. IPCC Fourth Assessment Report (AR4).

Mirza, M. M. Q. (2003). Climate change and extreme weather events: can developing countries adapt?. Climate policy, 3(3), 233-248.

Moscardi, E., \& De Janvry, A. (1977). Attitudes toward risk among peasants: an econometric approach. American Journal of Agricultural Economics, 59(4), 710-716.

Mugi-Ngenga, E. W., Mucheru-Muna, M. W., Mugwe, J. N., Ngetich, F. K., Mairura, F. S., \& Mugendi, D. N. (2016). Household's socio-economic factors influencing the level of adaptation to climate variability in the dry zones of Eastern Kenya. Journal of Rural Studies, 43, 49-60.

NDMA, Pakistan (2011) Annual Report 2011, National Disaster Management Authority Pakistan. http://www.ndma.gov.pk/

NDMA, Pakistan (2014) Annual Report 2014, National Disaster Management Authority Pakistan. http://www.ndma.gov.pk/

NDMA, Pakistan (2018) Annual Report 2018, National Disaster Management Authority Pakistan. http://www.ndma.gov.pk/

Ogurtsov, V. A., Van Asseldonk, M. P. A. M., \& Huirne, R. B. M. (2008). Assessing and modelling catastrophic risk perceptions and attitudes in agriculture: a review. NJASWageningen Journal of Life Sciences, 56(1-2), 39-58.

Olarinde L. O., Manyong V. M., Akintola J. O. (2007): Attitudes Towards Risk among Maize Farmers in the Dry Savanna Zone of Nigeria: Some Prospective Policies for Improving Food Production. African Journal of Agricultural Research, 2(8), 399-408.

PBS (2017). Economic Survey of Pakistan 2016-2017 Pakistan Bureau of Statistics, Ministry of

PBS (2019). Economic Survey of Pakistan 2018-2019 Pakistan Bureau of Statistics, Ministry of Finance Statistical Division, Government of Pakistan

PBS (2020). Economic Survey of Pakistan 2019-2020 Pakistan Bureau of Statistics, Ministry of Finance Statistical Division, Government of Pakistan

PDMA Punjab (2017) Annual Report 2017, Provincial Disaster Management Authority Punjab Pakistan. https://pdma.punjab.gov 
PDMA Punjab (2018) Annual Report 2018, Provincial Disaster Management Authority Punjab Pakistan. https://pdma.punjab.gov

PDMA Punjab (2019) Annual Report 2019, Provincial Disaster Management Authority Punjab Pakistan. https://pdma.punjab.gov

PDMA, Punjab (2014) Monsoon Contingency Plan Punjab 2014, Punjab Provincial Disaster Management Authority (PDMA) Government of Punjab, Pakistan.

PMD, (2019). Monthly weather report, 2019. National weather forecasting centre pakistan meteorologcal department (PMD) Islamabad, Government of Pakistan. http://nwfc.pmd.gov.pk/new/asset s/month ly-weath er-repor ts/2019-08.pdf publications/Annual\%20Report\%202018.pdf

Pratt J. W. (1964): Risk Aversion in the Small and in the Large. Econometrica: Journal of the Econometric Society, 32(1/2), 122-136.

Qasim, S., Khan, A. N., Shrestha, R. P., \& Qasim, M. (2015). Risk perception of the people in the flood prone Khyber Pukhthunkhwa province of Pakistan. International Journal of Disaster Risk Reduction, 14, 373-378.

Rafiq, L., \& Blaschke, T. (2012). Disaster risk and vulnerability in Pakistan at a district level. Geomatics, Natural Hazards and Risk, 3(4), 324-341.

Rana, I. A., \& Routray, J. K. (2016). Actual vis-à-vis perceived risk of flood prone urban communities in Pakistan. International Journal of Disaster Risk Reduction, 19, 366-378.

Raskin R., Cochran M. J.(1986): Interpretations and transformations of scale for the Pratt Arrow absolute risk aversion coefficient: implications for generalized stochastic dominance, West. J. Agric. Econ. 204-210.

Rehima, M., Belay, K., Dawit, A., \& Rashid, S. (2013). Factors affecting farmers' crops diversification: Evidence from SNNPR, Ethiopia. International Journal of Agricultural Sciences, 3(6), 558-565.

Rizwan, M., Ping, Q., Saboor, A., Ahmed, U. I., Zhang, D., Deyi, Z., \& Teng, L. (2020). Measuring rice farmers' risk perceptions and attitude: Evidence from Pakistan. Human and Ecological Risk Assessment: An International Journal, 26(7), 1832-1847.

Saqib, S. E., Ahmad, M. M., Panezai, S., \& Rana, I. A. (2016). An empirical assessment of farmers' risk attitudes in flood-prone areas of Pakistan. International Journal of Disaster Risk Reduction, 18, 107-114. 
Saqib, S. E., Arifullah, A., \& Yaseen, M. (2021). Managing farm-centric risks in agricultural production at the flood-prone locations of Khyber Pakhtunkhwa, Pakistan. Natural Hazards, 1-19.

Schlenker, W., \& Lobell, D. B. (2010). Robust negative impacts of climate change on African

Sarwar, B., \& Saeed, R. (2013). Risk perception and risk management strategies by farmers in agriculture sector of pakistan. Scientific Papers Series: Management, Economic Engineering in Agriculture and Rural Development, 13(3), 267-270. agriculture. Environmental Research Letters, 5(1), 014010.

Seo, S. N., \& Mendelsohn, R. (2008). An analysis of crop choice: Adapting to climate change in South American farms. Ecological economics, 67(1), 109-116.

Sherrick, B. J., Barry, P. J., Ellinger, P. N., \& Schnitkey, G. D. (2004). Factors influencing farmers' crop insurance decisions. American journal of agricultural economics, 86(1), 103-114.

Smidts, A. (1990). Decision making under risk: a study of models and measurement procedures with special reference to the farmer's marketing behavior. Agricultural University.

Teo, M., Goonetilleke, A., Ahankoob, A., Deilami, K., \& Lawie, M. (2018). Disaster awareness and information seeking behaviour among residents from low socio-economic backgrounds. International journal of disaster risk reduction, 31, 1121-1131.

Torkamani, J. (2005). Using a whole-farm modeling approach to assess prospective technologies under uncertainty. Agricultural systems, 85(2), 138-154.

Ullah, R. (2014). Production Risk Management and Its Impacts at the Farm Level: The Case of Paksitan. Doctor(Doctoral dissertation, Ph. D. Thesis), Asian Institute of Technology).

Ullah, R., \& Shivakoti, G. P. (2014). Adoption of on-farm and off-farm diversification to manage agricultural risks: Are these decisions correlated?. Outlook on Agriculture, 43(4), 265-271.

Ullah, R., Jourdain, D., Shivakoti, G. P., \& Dhakal, S. (2015). Managing catastrophic risks in agriculture: simultaneous adoption of diversification and precautionary savings. International Journal of Disaster Risk Reduction, 12, 268-277.

Ullah, R., Shivakoti, G. P., Rehman, M., \& Kamran, M. A. (2015). Catastrophic risks management at farm: the use of diversification, precautionary savings and agricultural credit. Pakistan Journal of Agricultural Sciences, 52(4). 
United Nations (2011) Pakistan floods: one year on 2011. A Report by the United NationsPakistan, Islamabad. $\quad$ http://unportal.un.org.pk/sites/unpakistan/pages/default.aspx. Accessed 7 Aug 2013

Van Winsen, F. (2014). Rethinking farmers' intended risk behaviour: the role of risk perception, risk attitude and decision context (Doctoral dissertation, Ghent University).

781 Velandia, M. M., Rejesus, R. M., Knight, T. O., \& Sherrick, B. J. (2009). Factors affecting farmers' utilization of agricultural risk management tools: the case of crop insurance, forward contracting, and spreading sales. Journal of agricultural and applied economics, 41(1379-2016-112752), 107-123.

Wang, J. X., \& Roush, M. L. (2000). What every engineer should know about risk engineering and management. CRC Press.

World Bank. (2013). Turn down the heat: Climate extremes, regional impacts, and the case for resilience.

792 Zhang, S., Hua, D., Meng, X., \& Zhang, Y. (2011). Climate change and its driving effect on the runoff in the "Three-River Headwaters" region. Journal of Geographical Sciences, 21(6), 963-978.

Zulfiqar, F., Ullah, R., Abid, M., \& Hussain, A. (2016). Cotton production under risk: a 797 


\section{Figures}

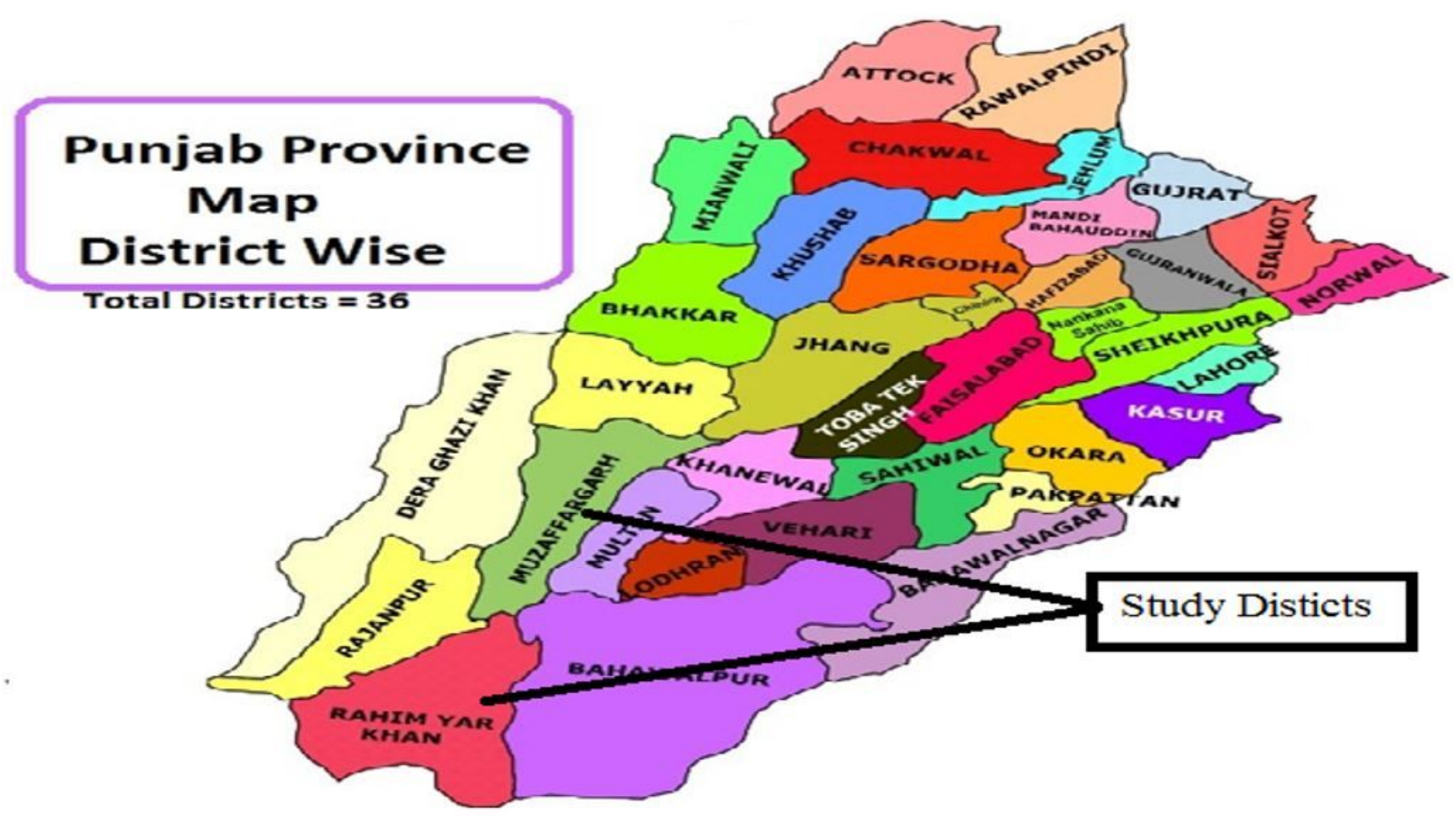

Figure 1

Study districts of Punjab province of Pakistan Note: The designations employed and the presentation of the material on this map do not imply the expression of any opinion whatsoever on the part of Research Square concerning the legal status of any country, territory, city or area or of its authorities, or concerning the delimitation of its frontiers or boundaries. This map has been provided by the authors. 


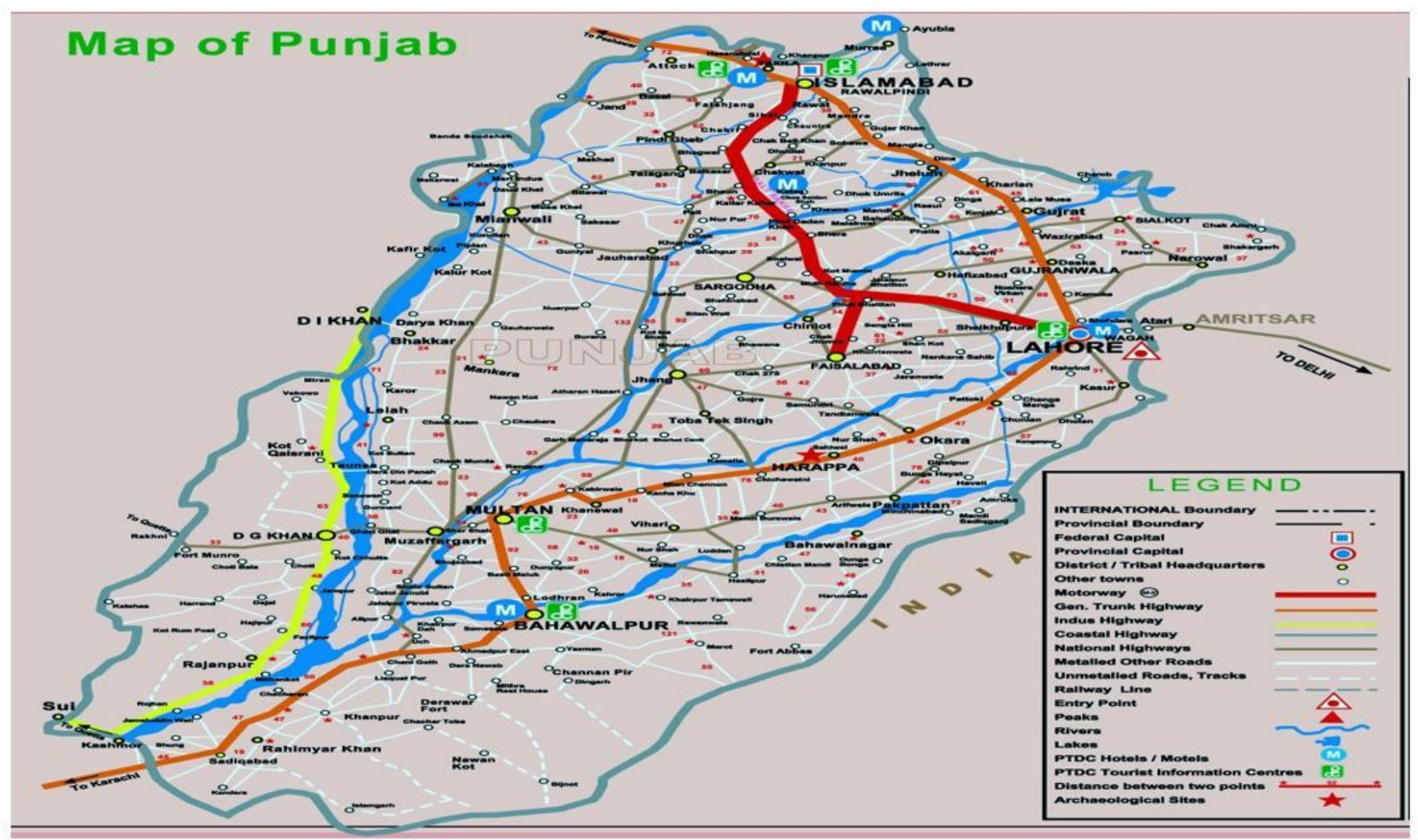

Figure 2

Punjab province and study districts Muzaffargarh and Rahim Yar Khan rivers flows Note: The designations employed and the presentation of the material on this map do not imply the expression of any opinion whatsoever on the part of Research Square concerning the legal status of any country, territory, city or area or of its authorities, or concerning the delimitation of its frontiers or boundaries. This map has been provided by the authors. 


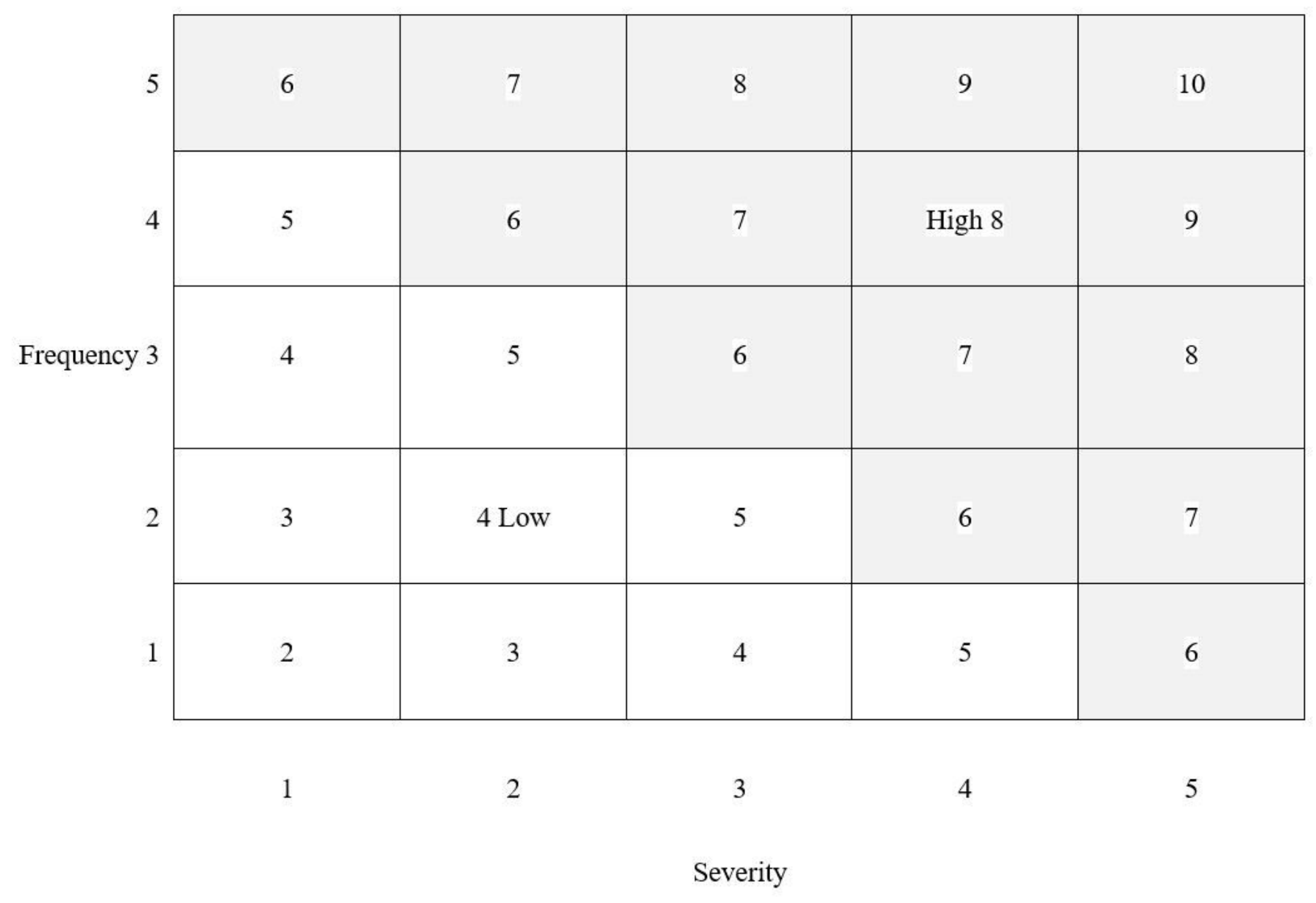

Figure 3

Farmers risk matrix

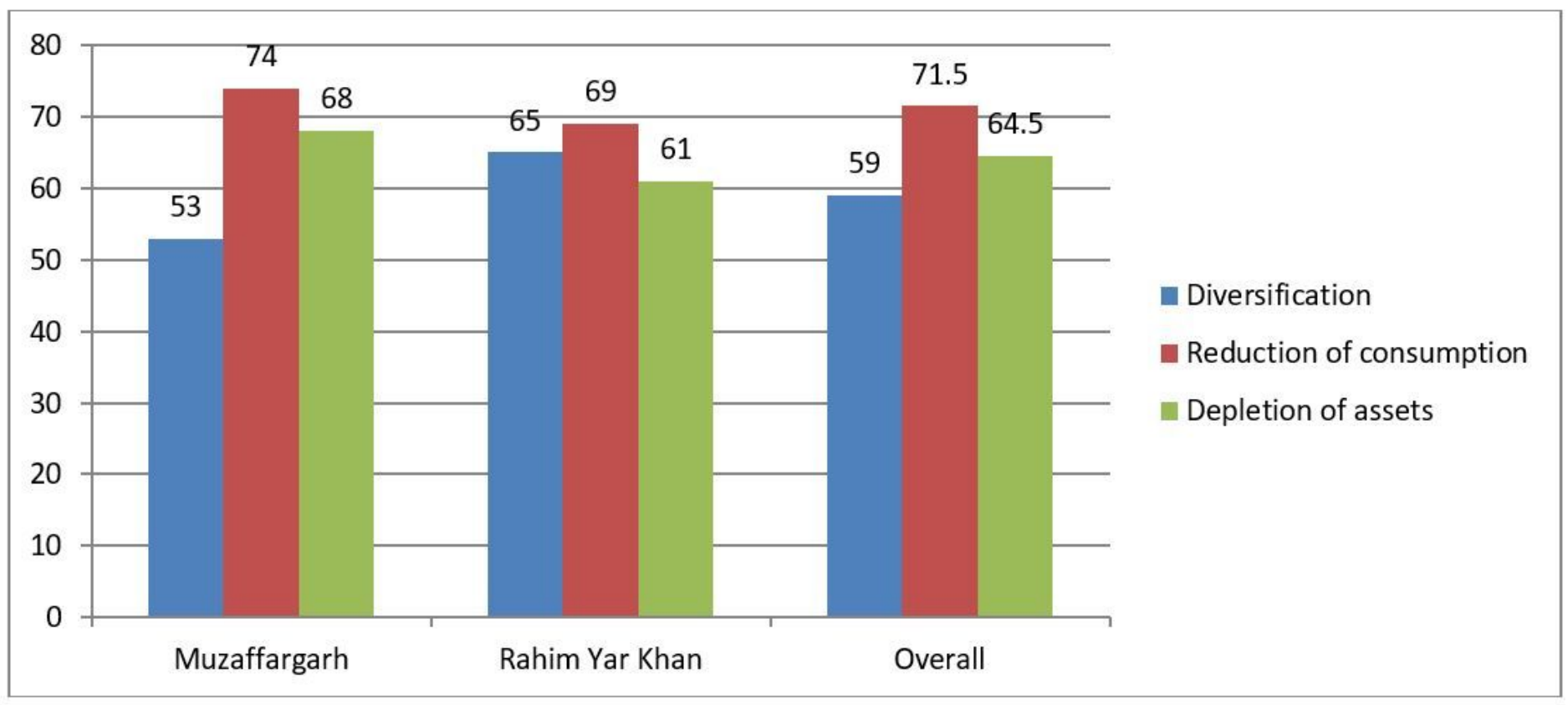

Figure 4 
Strategies adopted in both districts Muzaffargarh, Rahim Yar Khan and over all scenario

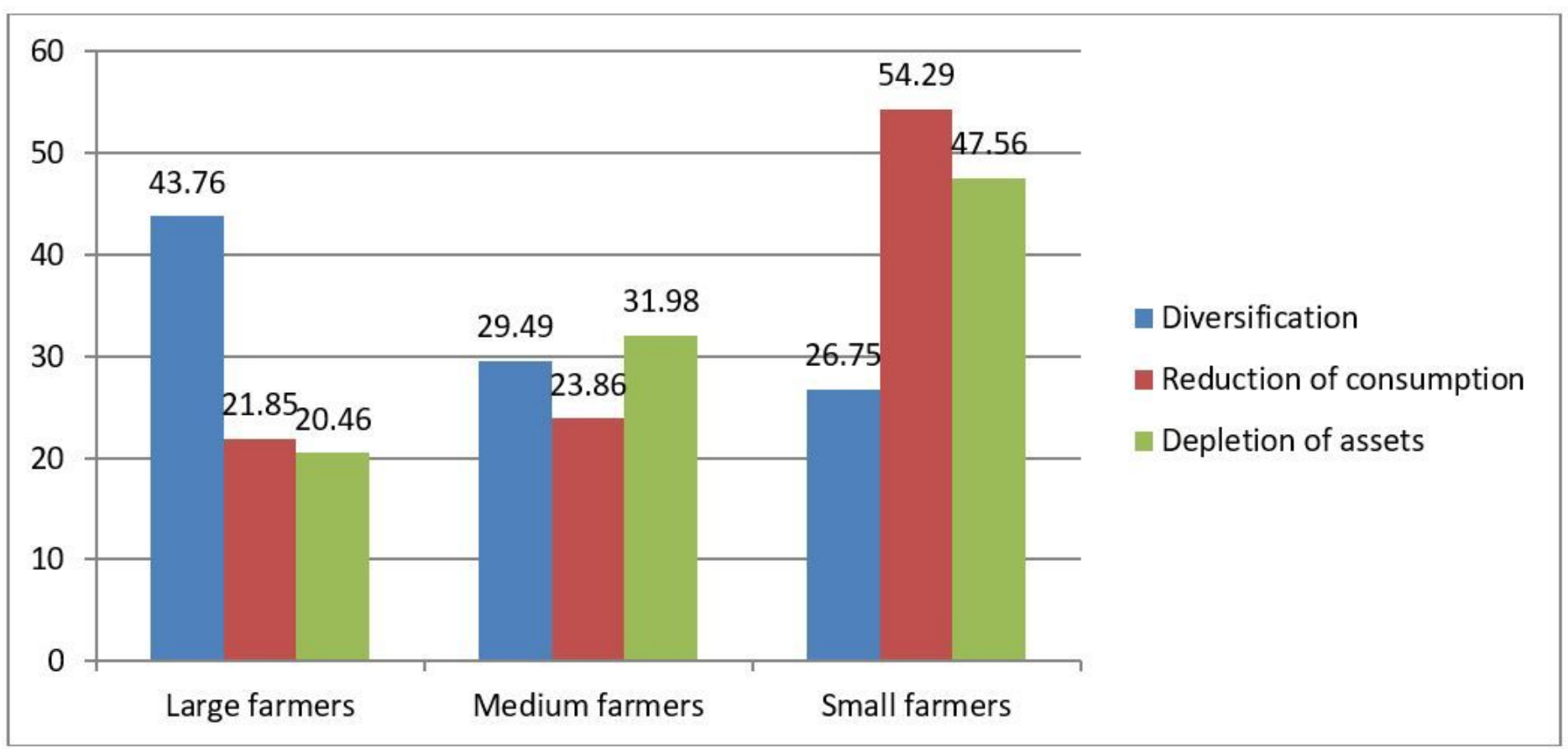

Figure 5

Strategies adopted by categorized farmers groups 